\title{
EFEKTIVITAS MODEL STAD (STUDENT TEAM ACHIEVEMENT DIVISION) TERHADAP PRESTASI BELAJAR STATISTIKA DASAR DITINJAU DARI AKTIVITAS BELAJAR MAHASISWA PADA POKOK BAHASAN DISTRIBUSI PELUANG DISKRIT
}

\author{
Ika Krisdiana \\ Dosen Prodi Matematika IKIP PGRI Madiun \\ Email: ikakrisdiana56@gmail.com
}

\begin{abstract}
Abstrak. Penelitian ini bertujuan untuk mengetahui : (1) Keefektifan model pembelajaran kooperatif tipe STAD (Student Teams Achievement Divisions) dengan pembelajaran langsung. (2) Perbedaan prestasi belajar antara mahasiswa dengan aktivitas tinggi, sedang dan rendah. (3) Perbedaan prestasi mahasiswa dengan aktivitas tinggi, sedang dan rendah pada pembelajaran kooperatif tipe STAD. (4) Perbedaan prestasi mahasiswa dengan aktivitas tinggi, sedang dan rendah pada pembelajaran langsung. (5) Efektivitas pembelajaran kooperatif tipe STAD dengan pembelajaran langsung pada mahasiswa dengan aktivitas tinggi. (6) Efektivitas pembelajaran kooperatif tipe STAD dengan pembelajaran langsung pada mahasiswa dengan aktivitas sedang. (7) Efektivitas pembelajaran kooperatif tipe STAD dengan pembelajaran langsung pada mahasiswa dengan aktivitas rendah.

Teknik pengambilan sampel dilakukan dengan cara sampling random stratifikasi (stratified random sampling) dan sampling random kluster (cluster random sampling). Pengujian hipotesis menggunakan Anava dua jalan dengan sel tak sama, dengan taraf signifikansi $5 \%$. Sebelumnya dilakukan uji prasyarat yaitu Uji Normalitas menggunakn Uji Liliefors dan Uji Homogenitas menggunakan Uji Bartlett.

Dari hasil analisis disimpulkan : (1) prestasi mahasiswa dengan pembelajaran STAD lebih baik daripada pembelajaran langsung. (2) mahasiswa dengan aktivitas tinggi mempunyai prestasi belajar lebih baik daripada mahasiswa dengan aktivitas sedang dan rendah. (3) mahasiswa dengan aktivitas tinggi prestasinya lebih baik daripada mahasiswa dengan aktivitas rendah dan sedang jika diajar dengan pembelajaran STAD. (4) mahasiswa dengan aktivitas tinggi, sedang dan rendah mempunyai prestasi yang sama jika diajar dengan pembelajaran langsung. (5) mahasiswa dengan aktifitas tinggi jika diajar dengan pembelajaran STAD memberikan prestasi yang lebih baik daripada pembelajaran langsung. (6) mahasiswa dengan aktivitas sedang memberikan prestasi yang sama jika diajar dengan pembelajaran STAD maupun pembelajaran langsung. (7) mahasiswa dengan aktivitas sedang memberikan prestasi yang sama diajar dengan pembelajaran STAD maupun pembelajaran langsung.
\end{abstract}

Kata Kunci: STAD, Kooperative, Aktivitas belajar

\section{PENDAHULUAN}

Kualitas kehidupan bangsa Indonesia sangat ditentukan oleh faktor pendidikan. Dengan pendidikan akan mencetak manusia yang berkualitas dalam mengikuti perkembangan tek dan informasi yang pesat. Untuk meningkatkan mutu Sumber Daya Manusia (SDM) agar mampu bersaing maka mutu pendidikan juga perlu ditingkatkan. Dalam rangka untuk meningkatkan mutu pendidikan dapat melalui tiga jalur yaitu jalur pendidikan sekolah, jalur pendidikan luar sekolah dan jalur pendidikan keluarga.

Masalah mendasar yang dihadapi dalam dunia pendidikan di Indonesia sekarang adalah bagaimana meningkatkan kualitas pendidikan. Kualitas pendidikan selalu dikaitkan dengan pencapaian prestasi belajar yang diperoleh peserta didik yang diidentifikasikan dengan skor hasil tes. Selain itu juga kualitas pendidikan tidak dapat terlepas dari 
kualitas proses pembelajaran yang dilakukan dosen.

Selain penggunaan metode pembelajaran juga terdapat faktor-faktor yang mempengaruhi keberhasilan belajar statistika dasar, diantaranya aktivitas belajar statistika dasar.

Salah satu metode pembelajaran yang digunakan dalam kegiatan belajar mengajar adalah model pembelajaran kooperatif tipe STAD (Student Team Achivement Division). Model pembelajaran kooperatif tipe STAD (Student Team Achivement Division) ini ide dasar pembelajarannya adalah bagaimana memotivasi mahasiswa dalam kelompok agar mereka dapat saling membantu dan mendorong satu sama lain dalam menguasai materi yang disajikan

\section{METODOLOGI PENELITIAN}

Penelitian ini termasuk penelitian eksperimental semu karena peneliti tidak mungkin mengontrol atau memanipulasi semua variabel yang relevan kecuali beberapa dari variabel-variabel yang diteliti. Hal ini sesuai dengan pendapat Budiyono (2003 : 82) bahwa "Tujuan penelitian eksperimental semu adalah untuk memperoleh informasi yang merupakan perkiraan bagi informasi yang dapat diperoleh dengan eksperimen yang sebenarnya dalam keadaan yang tidak memungkinkan untuk mengontrol dan/atau memanipulasikan semua variabel yang relevan". Rancangan yang digunakan adalah rancangan faktorial 2 $\mathrm{x} 3$, untuk mengetahui pengaruh dua variabel bebas terhadap variabel terikat:
Rancangan Penelitian

\begin{tabular}{cccc}
\hline B & \multicolumn{3}{c}{ Aktivitas belajar } \\
peserta didik
\end{tabular}

HASIL PENELITIAN

hasil anaanalisis Uji Keseimbangan untuk kemampuan awal pada kelompok eksperimen dan kelompok kontrol menunjukkan $\mathrm{H}_{0}$ diterima karena $t_{\text {obs }}=0,1915 \notin D K$. Hasil analisis $\mathrm{Uji}$ Normalitas untuk kemampuan awal pada kelompok eksperimen menunjukkan $\mathrm{H}_{0}$ diterima karena $\mathrm{L}_{\mathrm{obs}}=0,0664 \notin \mathrm{DK}$. Uji Homogenitas untuk kemampuan awal pada kelompok eksperimen dan kelompok kontrol menunjukkan $\mathrm{H}_{0}$ diterima karena $\chi_{\mathrm{obs}}^{2}=0,3094 \notin \mathrm{DK}$.

Dari hasil rangkuman analisis variansi menunjukkan bahwa efek faktor A (pendekatan pembelajaran metode STAD dan pembelajaran Langsung) terhadap variabel terikat, $\mathrm{H}_{0(\mathrm{~A})}$ ditolak. Hal ini berarti terdapat perbedaan perbedaan prestasi belajar antara pendekatan pembelajaran STAD dan metode Langsung terhadap prestasi belajar mahasiswa. efek faktor B (kategori Aktivitas) terhadap variabel terikat, $\mathrm{H}_{0(\mathrm{~B})}$ ditolak. Berarti terdapat perbedaan prestasi belajar pada mahasiswa kelompok aktivitas tinggi, aktivitas sedang dan aktivitas rendah. Kombinasi efek faktor A dan B terhadap variabel terikat, $\mathrm{H}_{0(\mathrm{AB})}$ ditolak. Berarti ada interaksi yang signifikan antara penggunaan pendekatan metode dan kategori aktivitas terhadap prestasi belajar mahasiswa. 


\section{Kesimpulan}

Berdasarkan hasil analisis data dan pembahasan di atas dapat disimpulkan bahwa: (1) Prestasi belajar statistika dasar mahasiswa pada pokok bahasan distribusi peluang diskrit dengan menggunakan metode pembelajaran STAD (Student Team Achievement Division) lebih baik dari pada prestasi belajar statistika dasar mahasiswa dengan menggunakan pembelajaran langsung. (2) Prestasi belajar mahasiswa pada pokok bahasan distribusi peluang diskrit yang mempunyai aktivitas tinggi lebih baik prestasinya dari pada mahasiswa yang mempunyai aktivitas rendah, dan mahasiswa yang mempunyai aktivitas sedang prestasinya lebih baik dari pada mahasiswa yang mempunyai aktivitas rendah tapi untuk mahasiswa yang mempunyai aktivitas timggi prestasinya sama dengan mahasiswa yang mempunyai

aktivitas sedang. (3) Prestasi belajar statistika dasar mahasiswa yang mempunyai aktivitas tinggi lebih baik dari pada mahasiswa yang mempunyai aktivitas rendah pada pembelajaran kooperatif STAD, berbeda untuk mahasiswa yang mempunyai aktivitas sedang dan rendah mempunyai prestasi belajarnya sama. (4) Prestasi belajar statistika dasar mahasiswa yang mempunyai aktivitas tinggi, sedang atau rendah sama pada pembelajaran langsung. (5) Prestasi belajar statistika dasar pada mahasiswa kelompok aktivitas tinggi yang menggunakan pembelajaran STAD lebih baik dari pada mahasiswa yang menggunakan pembelajaran langsung. (6) Prestasi belajar statistika dasar pada mahasiswa kelompok aktivitas sedang mempunyai prestasi yang sama baik menggunakan pembelajaran STAD maupun menggunakan pembelajaran langsung. (7) Prestasi belajar statistika dasar pada mahasiswa kelompok aktivitas rendah mempunyai prestasi yang sama baik menggunakan pembelajaran STAD maupun menggunakan pembelajaran langsung.

\section{DAFTAR PUSTAKA}

Armtrong, Scott. 1998. Student Teams Achievement Divisions (STAD) in a Twelfth Grade Classroom: Effect of Student Achievement and Attitude. Journal of Social Studies Research. http://findarticles.com/p/articles/mi_qa3 823/is_199804

Asri Budiningsih. 2005. Belajar dan Pembelajaran. Jakarta: Rineka Cipta

Budiyono. 2003. Metodologi Penelitian Pendidikan. Surakarta. UNS Press

Budiyono. 2004. Statistik untuk Penelitian. Surakarta. UNS Press

Budiyono. 2007. Peningkatan Kualitas Pembelajaran Statistika dasar melalui Penilaian yang Efektif. Surakarta. UNS Press

Depdiknas. 2003. Kurikulum Berbasis Kompetensi. Standar Kompetensi Mata Pelajaran Statistika dasar Sekolah Menengah Pertama dan Madrasah Tsanawiyah. Pusat Kurikulum Balitbang Depdiknas

Effandi Zakaria and Zanaton Iksan. 2006. Promoting Cooperative Learning in Science and Mathematics. Education : A Malaysian Perspective. Eurasia Journal of Mathematics, Science \& Technology education 3(1), 35-39. ISSN: $1305-8223$

Eggen, D. Paul, Kauchak and P. Fonald. 1993. Strategies for teachers, Teaching Content and Thingking skill. Boston: Allynand Bacon Publisher

Francis A Adesoji, tunde L Ibraheem. 2009. Effect of Student Teams Achievement Divisions Strategy and Mathematics knowlegde on Learning 
Outcomes in Chemical kinetics. The Journal of International Social Research. Volume 2/6

Henny Ekana Chrisnawati. 2005. Pengaruh Penggunaan Metode Pembelajaran Kooperatif Tipe STAD (Student Teams Achievement Divisions) Terhadap Kemampuan Problem Solving Mahasiswa SMK (Teknik) Swasta Di Surakarta DiTinjau Dari Motivasi Belajar Mahasiswa: Thesis UNS Surakarta

Ira Kurniawati. 2003. Pengaruh Metode Pembelajaran Kooperatif Jigsaw Terhadap Prestasi Belajar Statistika dasar Ditinjau dari Aktivitas Belajar Mahasiswa Kelas II SLTP Negeri Surakarta: Thesis UNS Surakarta

Oemar Hamalik. 2003. Kurikulum dan Pembelajran. Bandung: Bumi Aksara

Poerwodarminto. 1994. Kamus Besar Bahasa Indonesia. Jakarta: Balai pustaka

Purwoto. 2003. Strategi Belajar Mengajar Statistika dasar. Surakarta: UNS Press
Robert A. Lonning. 1993. Effect of Coopertive Learning Strategies on Student Verbal Interactions and Achievement during Conceptual Change Instruction in $10^{\text {th }}$ Grade General Science. Journal Of Research In Science Theaching. Vol. 30. No. 9. PP. 10871101

Saifuddin, A. 1996. Tes Prestasi. Yogyakarta: Pustaka Pelajar

Sardiman, A. M. 2004. Interaksi dan Motivasi belajar Mengajar. Jakarta: Raja Grafindo persada

Shafqat Ali Khan. 2008. The Effect of Cooperative Learning on Reading, Writing Achievement and Academic Self-Esteem. Journal of Educational research. Vol. 11. No.1 2008 Dept of Education IUB, Pakistan.

Slameto. 2003. Belajar dan FaktorFaktor yang Mempengaruhinya. Jakarta: Rineka Cipta

Slavin. 1995. Cooperative Learning, Theory and Practice $4^{\text {th }}$ edition. Allyn an bacon Publishers 